\title{
Earthquake Early Warning Systems
}

\section{Pei-Yang Lin}

National Center for Research on Earthquake Engineering, National Applied Research Laboratories (NARL), Taiwan (Received 9 September 2011; Published on line 1 December 2011)

Corresponding author: pylin@ncree.narl.org.tw

DOI: $10.5875 /$ ausmt.v1i2.123

Abstract: Because of Taiwan's unique geographical environment, earthquake disasters occur frequently in Taiwan. The Central Weather Bureau collated earthquake data from between 1901 and 2006 (Central Weather Bureau, 2007) and found that 97 earthquakes had occurred, of which, 52 resulted in casualties. The 921 Chichi Earthquake had the most profound impact. Because earthquakes have instant destructive power and current scientific technologies cannot provide precise early warnings in advance, earthquake prevention is crucial. The earthquake early warning system can provide seconds to tens of seconds of warning time before an earthquake strikes. This paper introduces the earthquake early warning system build by Taiwan National Center for Research on Earthquake Engineering and a practice case happened in Yilan City, Taiwan.

Keywords: Earthquake; disaster; earthquake early warning system

\section{Introduction}

Taiwan is located on the Circum-Pacific seismic belt at the junction of the Eurasian Plate and the Philippine Sea Plate. Geological activities are frequent in Taiwan, with more than 4,000 earthquakes of various scales, including over 200 sensible earthquakes, on average each year. The earliest seismic occurrence can be traced to the Wanli period of the Ming Dynasty. Over the past hundred years, a number of majorly disastrous earthquakes have occurred in Taiwan. A significant earthquake in Hsinchu and Taichung in 1935 resulted in the death of 3,276 people, over 12,000 people were injured, more than 17,000 buildings collapsed, and over 36,000 buildings half collapsed. Earthquakes occurred in Chiayi in 1940, in Tainan in 1946, and in Tainan and Chiayi in 1964. The 921 Chichi Earthquake in 1999 resulted in the death of 2,434 people and nearly 11,000 buildings collapsed. Though each of these earthquakes caused heavy casualties and property losses, modern scientific technologies remain unable to predict earthquakes and make evacuation plans. Seismological monitoring networks, historical earthquake data, and local geological conditions are required to determine potential hazardous areas and plan earthquake rescue measures.

The United States and Mexico have started to develop earthquake early warning systems. In 1989, the U.S. Geological Survey (USGS) installed an early warning system that detects aftershocks in California where earthquakes have caused profound disruption. The early warning system uses the existing earthquake network to receive aftershock signals, and then transmits aftershock information to rescue personnel using radio signals. After a severe earthquake in 1985, which caused more than 10,000 casualties, Mexico installed a series of seismometers along the coastline on the seismic belt in the open sea. As an earthquake occurs and the seismometers along the coastline receive signals, the earthquake information is transmitted through a proprietary radio signal to Mexico City hundreds of kilometers away to prompt relevant preparations for the earthquake. The system successfully issued an earthquake warning $72 \mathrm{~s}$ prior to the S-band attack in Mexico City during the 7.3-magnitude earthquake in 1995. 
Similar to Taiwan, Japan is located on the Pacific seismic belt and is profoundly affected by earthquakes. The Japan Meteorological Agency (JMA) constructed an Earthquake Early Warning (EEW) system in October 2007 to reduce earthquake disasters, and promoted the system throughout Japan. This EEW system can issue warnings mainly because of the concentration of seismic stations (approximately one station every $20 \mathrm{~km}$ ) established by the JMA and because computers can calculate rapidly the location of earthquakes and the direction of seismic wave propagation. Because seismic waves generated from seismic sources propagate within earth, the wave speed is affected by various stratum media of dissimilar features. Seismic waves can be divided into P-bands and S-bands. If the speed of P-bands is approximately 5 to $7 \mathrm{~km} / \mathrm{sec}$, the speed of S-bands, which can easily damage the earth's surface, is approximately 3 to $4 \mathrm{~km} / \mathrm{sec}$. This study develops an Earthquake Early Warning System (EEWS) by taking advantage of the superior speed of P-bands compared to the speed of S-bands. The EEWS estimates the arrival of $\mathrm{S}$-bands based on P-band information, and determines the potential impact of S-bands on the buildings within the S-band impact range to limit the impact of earthquakes on socioeconomics by improving the response time before an earthquake strikes.

\section{The Development of the Earthquake Early Warning System}

Because of its geographical features, earthquakes frequently occur in Taiwan. The Central Weather Bureau has established the Taiwan Strong Motion Instrumentation Program to detect earthquake activity. The P-bands and S-bands of an earthquake have different speeds; S-bands are closely related to the surface seismic intensity and the peak ground acceleration (PGA). Electronic signals travel at a speed similar to the speed of light. Although the speed of electronic signals is decreased by the transmission method and transmission

Dr. Pei-Yang Lin got his PH.D. from National Taiwan University, Civil Engineering in 2000. In the same year, he joined the faculty of National Center for Research on Earthquake Engineering. His research works on the structural control, system identification and structural health monitoring. In the past years, he had developed several structural control systems, including the active, passive and semi-active controlled bracing system, semi-active controlled isolation system with MR damper and Semi-Active controlled Mass Damper (SAMD) etc. He had also developed some adjustable passive dampers and isolator. In the recent years, he focuses on the development and application of Earthquake Early Warning System (EEWS). He had executed more than 40 shaking table tests and in charge of the shaking table in NCREE from 2011. He has published more than 21 journal papers and 52 conference papers and has one patent. His objectives, now and for the future, is to provide a safety structure to help people against earthquake hazard, and a early warning system to help people have enough time to get out of dangerous. media, it remains significantly faster than the speed of seismic waves. Therefore, seismic stations near an epicenter can be used to collect P-band data and transmit it to a computing core. The computing core then determines the impact of S-bands on the earth's surface through related algorithm and issues warnings to areas affected by the earthquake before violent vibrations begin.

The idea of using P-bands to monitor earthquake activities was proposed by Dr. Cooper (1868) in the U.S. The U.S. and Mexico had both developed earthquake early warning systems appropriate for the corresponding areas by the end of the nineteenth century. Additionally, Professor Hakuno conducted research in this field previously in Japan. In 2007, the JMA developed an Earthquake Early Warning System (EEWS) that collects data instantly from seismic stations near the epicenter through a seismological monitoring network with grids of approximately 20 square $\mathrm{km}$. The system then deduces the impact of the seismic waves of the earthquake and issues warnings to areas (areas further from the epicenter) where S-bands have not yet arrived. This operation model uses data from seismic stations to collectively calculate and estimate related parameters, such as the scale of an earthquake, the surface seismic intensity, and the arrival time of S-bands, and can be regarded as a wide area earthquake early warning system. The Central Weather Bureau is currently developing and testing the earthquake instant warning system using the auxiliary seismic stations (Taiwan Strong Motion Instrumentation Program, TSMIP) distributed throughout Taiwan.

The wide area earthquake early warning system collects seismic data using a large-scale seismological monitoring network. When an earthquake occurs, the system collects the data recorded by seismic stations around the epicenter to determine the relative impact of the earthquake. Because the transmission of seismic waves within earth is affected by dissimilar media, data of various stations are cross-analyzed to reduce deviations. Wide-range and high-density seismic stations can improve the accuracy of estimations made by the system. However, the use of multiple stations cannot provide early warnings to areas near the epicenter because the system requires time (approximately $18 \mathrm{~s}$ ) to process data from multiple stations during actual operation. Japan has also begun to develop on-site earthquake early warning systems (on-site EEWS) in recent years. On-site EEWS systems use existing seismometers to estimate and calculate earthquake-related warnings. In this system, because data of only one on-site seismometer is used, the calculation time is greatly reduced, providing rapid 
earthquake warnings. However, the accuracy of on-site EEWS is worse than that of regional earthquake warning systems. Therefore, the future trend in development is to combine regional and on-site earthquake early warning systems to reduce the blind zone and simultaneously maintain the accuracy of warning systems. Japan has begun using on-site warning systems to improve the response time of the earthquake early warning system in its strong earthquake warning system. A schematic diagram of the two systems is shown in Figure 1. Because the Central Weather Bureau has begun developing a regional EEWS system, the research aim of the National Center for Research on Earthquake Engineering is to develop an on-site EEWS.

As shown in Figure 1, the on-site EEWS the National Center for Research on Earthquake Engineering is currently developing can be divided into three main parts. The first part is an on-site early warning module that uses existing seismometers to detect P-bands. The detected data are subsequently calculated using algorithms to determine earthquake-related parameters, such as the scale, intensity, and arrival time. The second part is the structural quick response estimation module; this module can rapidly estimate structural responses and provide the estimated seismic intensity at each location of a building to facilitate the standard operating procedures for disasters. The final part is the applied research of earthquake warnings, which integrates the estimated parameters of the first two parts with simulations of various earthquake prevention conditions to construct and test a prototype plan for an automatic earthquake prevention system.

Long-term research plans involve the development and testing of a universal EEWS and an advanced EEWS targeting different warning user ends. The major service targets of universal EEWS are schools, government organizations, and residences. The aim is to develop an economical and rapid early earthquake warning system that can combine automatic warnings with a disaster reduction control system, such as turning of the gas automatically, evacuation route signal controls, stopping elevator operations in buildings, and guiding personnel evacuations. On-site EEWSs are limited to the use of instant data from a single seismic station to determine the earthquake parameters affected by S-bands. The data for on-site EEWS is far less than that of regional EEWS; consequently, the estimation accuracy of on-site EEWS is lower. Therefore, the preferred test subjects in the initial stage of this study are schools, because schools have a higher tolerance for false alarms. The major targets of advanced EEWS are crucial and valuable buildings and facilities. Advanced EEWSs can target each location and issue independent seismic intensity warnings using high-precision and multi-region structural rapid response estimation technologies. Automatic earthquake disaster prevention control system can be integrated to reduce the economic and personnel loss.

On-site earthquake early warning system

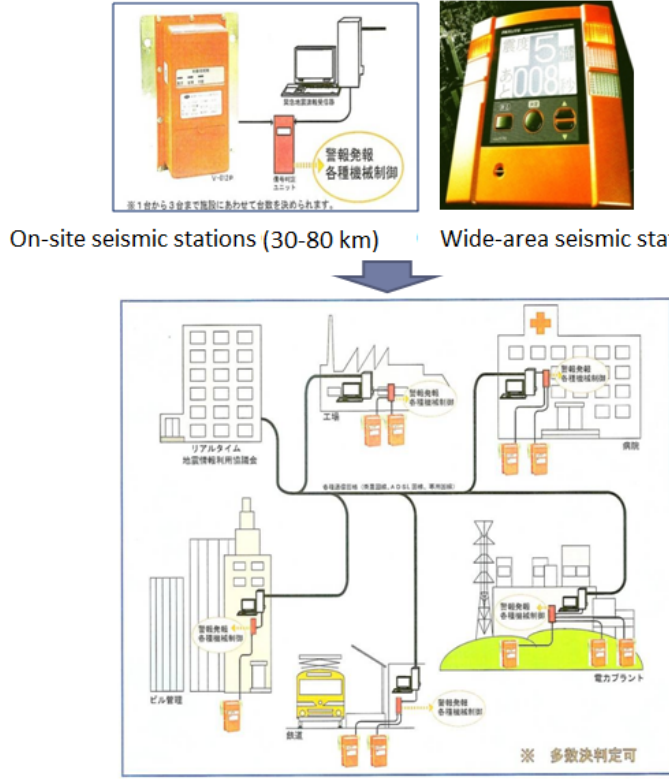

Existing systems in Japan

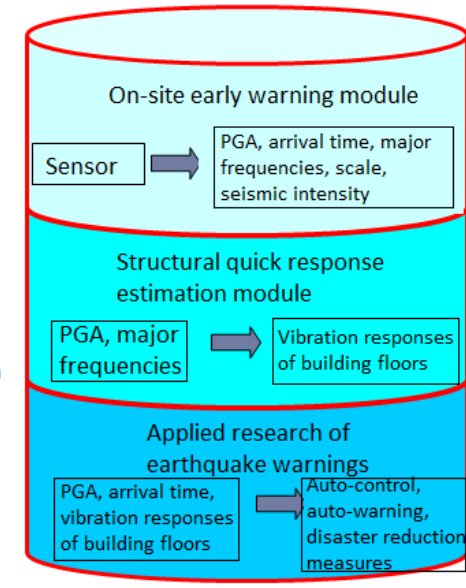

Universal EEWS

- Schools, government organizations - Estimation of vibration responses for each floor

- Auto-warning and disaster reduction controls

Advanced EEWS

- Crucial facilities, high-economic-value structures

- Cstimation of each structural location in response to earthquakes

- Automatic disaster reduction controls (to reduce economic losses)

Warning systems used in Taiwan

Figure 1. A schematic diagram of the earthquake warning systems of Taiwan and Japan. 


\section{Structures and Development of Systems}

\section{The Structure of Earthquake Warning Systems}

The National Center for Research on Earthquake Engineering was founded in 1990. Since then, it has been focused on studies related to estimating earthquake damage, designing seismic resistant buildings, and analyzing seismic bridge devices. After the 921 Earthquake in 1999, the center cooperated with various government units (for example, the Directorate General of Highways and the National Expressway Engineering Bureau), academic organizations, and related business organizations in the engineering community to conduct large-scale substantial studies of buildings and bridges affected by the earthquake. Because the Central Weather Bureau has already established a centralized seismography network and a regional earthquake early warning system, the regional system can monitor and calculate earthquake data based on data collected from seismometers distributed throughout Taiwan, and warning can be issued following the calculation. Data calculation requires time; for inland earthquakes, the average time for data processing is approximately 18 to $20 \mathrm{~s}$ on average. However, seismic waves can disperse a considerable distance during this period, and areas in proximity to epicenters (within a $50-$ to $70-\mathrm{km}$ radius) would not receive warnings before earthquakes arrive. These areas are called the "blind zone" of earthquake warning systems. The size of Taiwan is relatively small, the north-south orientation is approximately $300 \mathrm{~km}$ and the east-west orientation is approximately $100 \mathrm{~km}$. The epicenters of disastrous earthquakes are primarily located within the island; for example, the epicenter of the 921 Earthquake in 1999 was in Chichi Township along the south Provincial Highway. The calculated blind zone potentially includes regions as far north as Hsinchu County and as far south as Tainan County; this blind zone is also the areas hardest hit by earthquakes. Therefore, minimizing the blind zone is urgently required. Thus, the National Center for Research on Earthquake Engineering began developing an on-site earthquake early warning system. The system includes on-site immediate strong earthquake alarm modules, structural quick response estimation modules, the integration and test of embedded systems, customized display of earthquake warnings, and automatic disaster reduction controls.

\section{On-Site Instant Strong Earthquake Alarm Modules}

The National Center for Research on Earthquake Engineering has developed two methods, body-wave focal detection and an artificial neural network technique, for detecting micro P-bands that are imperceptible to humans before earthquakes strike. Using the signals of the wave profile, they estimate the seismic intensity and scale of subsequent earthquakes. These two methods have been used to study and test hundreds of thousands of earthquake records over the years in Taiwan; these methods have accurately and effectively estimated earthquake parameters, such as the scale and intensity of earthquakes.

\section{Structural Quick Response Estimation Modules}

In addition to earthquake-related studies, the National Center for Research on Earthquake Engineering has also conduct studies on the responses of structures to earthquakes, and has developed a technology for rapidly estimating structural responses. This quick estimation technology can estimate surface seismic intensities and other preset structure parameters, and calculate the seismic intensities of each location in each floor of a building within tens of microseconds. With this technology, the seismic intensity for each floor, whether it is the first or the fiftieth floor, can be instantly calculated to provide early warnings. The responses of any chosen location can also be customized according to the different requirements.

\section{Integrations and Tests of Embedded Systems}

Both the earthquake warning and quick estimation of structural responses have been verified by numerical analyses. The National Center for Research on Earthquake Engineering applied an embedded real-time calculation system (dSpace, Micro-box) to link the on-site high-precision seismometers and embed the warning technology into the real-time computing core to further implement the related technologies. Earthquake warning information, such as the estimated seismic intensity, can be provided by detecting the lead micro P-band vibration with high-precision seismometers and performing instant calculations. The entire system passed the vibration table test of the National Center for Research on Earthquake Engineering; thus, it can detect P-bands of an earthquake in real-time and provide warning messages such as the estimated seismic intensities. Consider the 921 Earthquake in 1999 for example, employing the system could provide an additional 7, 17, and $27 \mathrm{~s}$ of early warning time for Dali Township in Taichung County, the Hsinchu Science Park, and Da-an District in Taipei City, respectively (compared with the time differences provided by the earthquake early warning system used 
by the Taiwan High Speed Rail). The system has been implemented in Taipei, Yilan, and Chiayi successively for long-term on-site testing, and has successfully issued earthquake early warning information before earthquakes strike during the test period.

Customized Display of Earthquake Warnings and Automatic Disaster Reduction Control

The additional time an earthquake early warning system can provide is limited, tens of seconds at most, and is dependent on its distance from the earthquake epicenter. Therefore, effective use of the warning time to reduce the loss of lives and properties is also a crucial issue. The National Center for Research on Earthquake Engineering focused on the future potential usage environment and conducted expert forums and questionnaire surveys to discuss using this system in the following environments: general residential housing, construction sites, medical facilities, road transportation, railway transportation, airports and harbors, educational facilities, factories, disaster rescue units, power plants, and meeting places. The National Center for Research on Earthquake Engineering integrated the opinions of related government units, academic research groups, and private enterprises and organizations as aims of the earthquake early warning system to infer the potential market value of the earthquake industry in Taiwan. The National Center for Research on Earthquake Engineering has designed automatic disaster reduction controls and a customized warning display system according to the requirements of each user end after consolidated various opinions. This system issues earthquake information through methods such as automatic broadcasting, text banners, television alerts, and mobile phone messages to all users within the shortest possible time, and simultaneously turns off the gas, parks the elevators and opens their doors, switches to backup power, and provides evacuation route guidance. These measures enable users to focus on their personal safety and rapidly evacuate, shelter, and seek assistance. Then, the relevant device implements automatic disaster reduction control and provide an escape guide with voice instructions. The National Center for Research on Earthquake Engineering combined the on-site earthquake early warning system, automatic disaster reduction controls, and customized warning display system, and installed the systems in a two-story display house. They hosted a press conference to introduce the system to the public and media in February 2011.

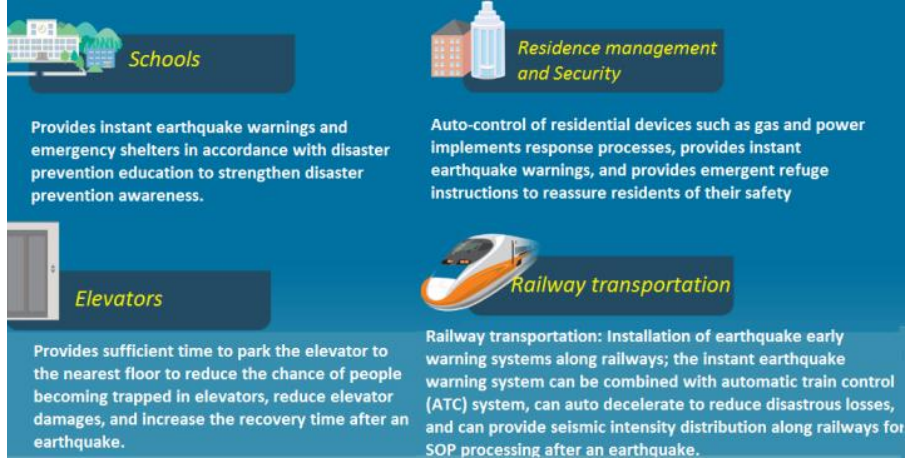

Figure 2. The applications of earthquake early warning systems.

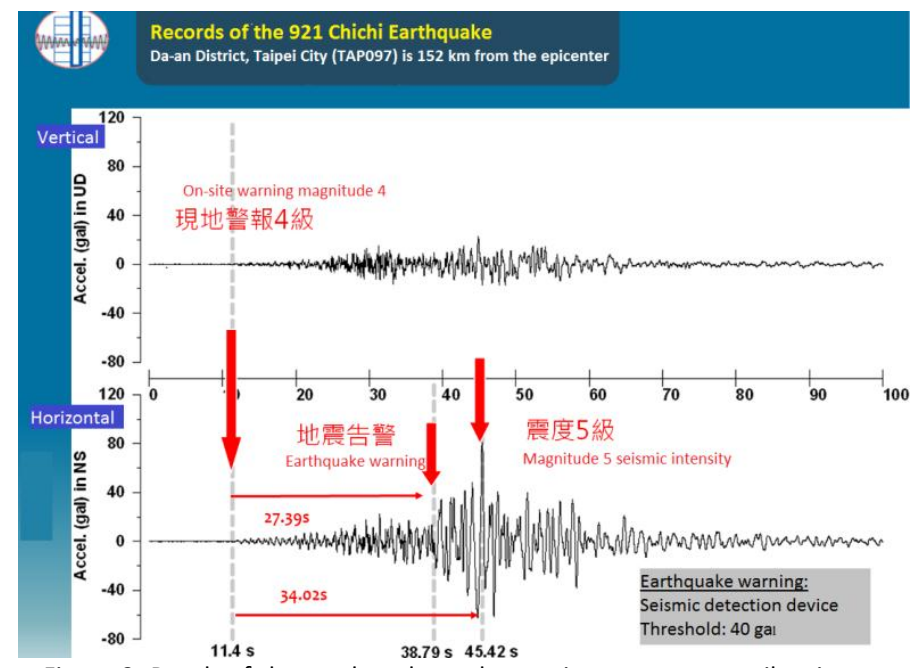

Figure 3. Result of the earthquake early warning system on a vibration table.

\section{Laboratory Verifications and Tests}

The feasibility and reliability of the entire on-site earthquake early warning system must be verified before it is implemented. The National Center for Research on Earthquake Engineering has progressively initiated integration tests since the end of 2009. The integrated system includes a high-precision seismometer, a data capture system, an embedded instant calculation core, and an automatic disaster reduction and warning display system. The high-precision seismometer, data capture system, and embedded instant computing core were first integrated into an "earthquake early warning core system," and installed on the triaxial vibration table of the National Center for Research on Earthquake Engineering for actual tests. The system was tested using the records of the 921 Earthquake in 1999 to verify the practical efficacy of the earthquake early warning system. Figure 3 shows that the earthquake early warning system could have issued a warning of seismic intensity $34.02 \mathrm{~s}$ before the greatest seismic wave of the 921 Earthquake arrived in Taipei County; compared to the existing warning system of the Taiwan High Speed Rail (with an acceleration threshold value of 40 gal), the earthquake 


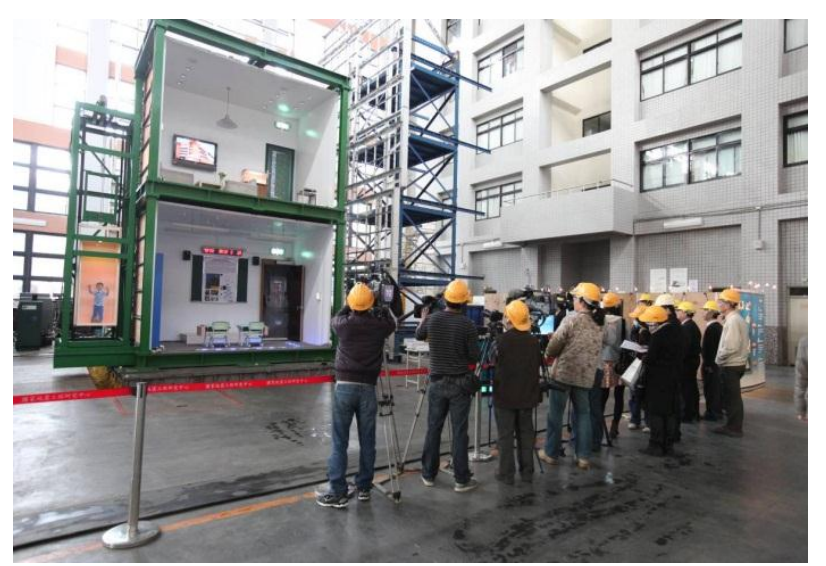

Figure 4. A photograph from the press conference introducing the earthquake early warning system.

early warning system provides an additional $27.3 \mathrm{~s}$ of warning time. After the earthquake early warning core system was verified, the National Center for Research on Earthquake Engineering tested the integration of the automatic warning display and disaster reduction control systems. A complete earthquake early warning system (including an earthquake early warning system, a warning display system, and an automatic disaster reduction control system) was installed on the triaxial vibration table in a full-size display house to simulate the earthquake conditions during the 921 Earthquake in Dali Township in Taichung County, the Hsinchu Science Park, and Taipei City to conduct integrated testing. In February 2011, the center also hosted a press conference to introduce this earthquake early warning system to the public at the National Center for Research on Earthquake Engineering.

The test results indicate that the system can issue early earthquake warnings before people perceive earthquakes, and can automatically provide earthquake early warning information using methods such as broadcasts, text banners, and television insertions. The system also automatically operates automatic disaster reduction controls, such as turning off gas, parking elevators, opening escape routes, turning on escape indicators, and switching to backup power. Thus, users will only need to shelter by following escape instructions and use the limited warning time effectively.

\section{On-Site Verification Tests}

To further verify the earthquake early warning system and to implement earthquake prevention education, this project established demonstration stations in Fanghe Junior High School in Taipei City, Yilan Elementary School in Yilan City, National Chung Cheng University in Chiayi, and the Luodong Branch of Secom.
Ltd. Automatic warning display systems were also designed and installed according to the needs at the user ends. Each of the demonstration stations can simultaneously receive regional earthquake early warning messages issued by the Central Weather Bureau and on-site earthquake warning messages provided by the National Center for Research on Earthquake Engineering. Figure 5 shows the on-site earthquake warning system installed in Chung Cheng University in Chiayi County. The requirements for delivering earthquake warnings were considered, and both Fanghe Junior High School and Yilan Elementary School can broadcast earthquake messages throughout the campus using special earthquake warning broadcast systems. Character generators for earthquake early warnings were also installed in key locations and meeting places to provide warnings in text. Group messages are sent to administrative staff to provide earthquake early warnings. While constructing the hardware, we also trained teachers and students to use the system for sheltering and evacuating before an earthquake occurs according to the earthquake prevention drill plan of each school. An earthquake prevention drill involving the entire school should be held once a year to reinforce awareness of earthquake prevention through practical operation.

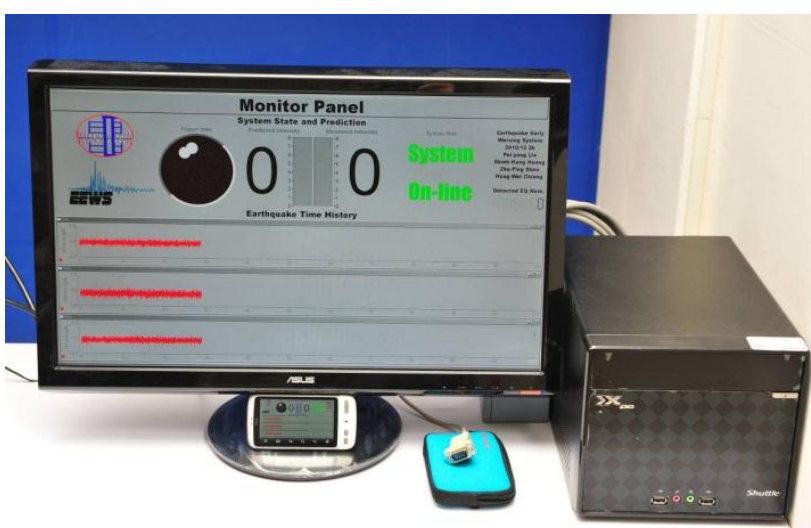

Figure 5. On-site earthquake early warning system (Chung Cheng University).

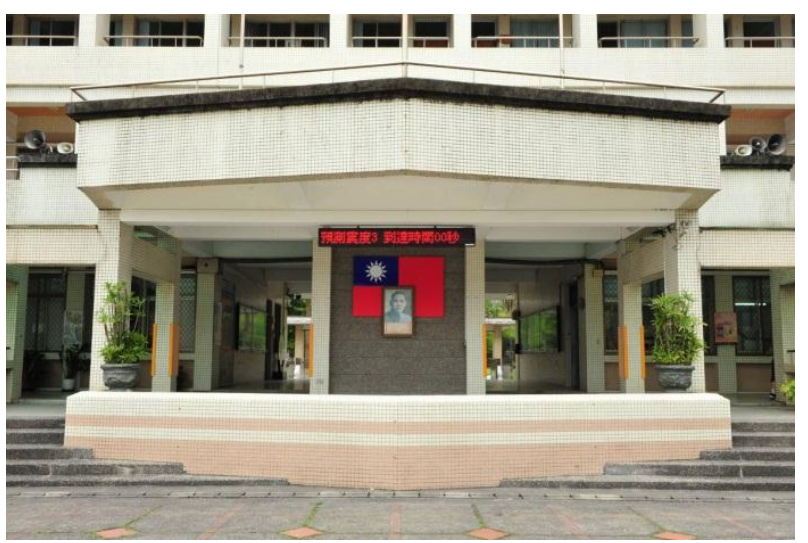

Figure 6. Character generator of the earthquake early warning system installed in Yilan Elementary School. 


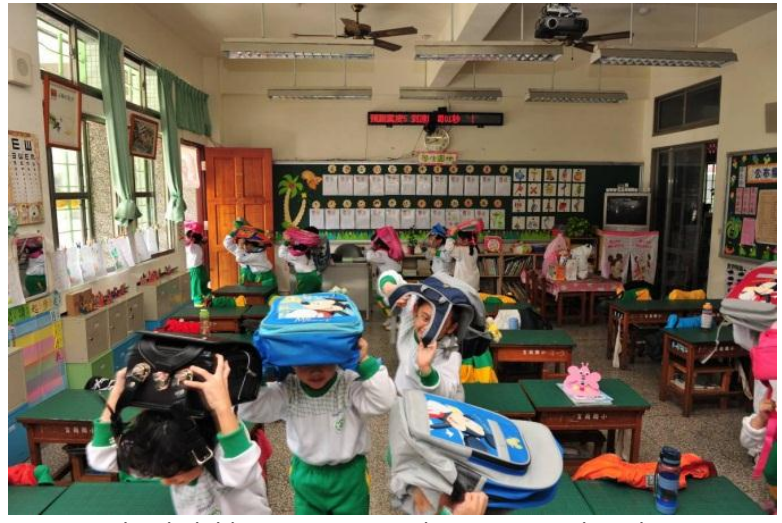

Figure 7. School children evacuating during an earthquake prevention drill in Yilan Elementary School.

A 5.8-magnitude sensible earthquake occurred at $10.1 \mathrm{~km}$ south east of Yilan County on April 30, 2011. The three seismic stations, Yilan Elementary School, Chung Cheng University, and Luodong Branch of Secom Ltd. all functioned normally and issued earthquake warnings. Figure 8 shows the measured records at Yilan Elementary School and Chung Cheng University with the south-north orientation and east-west orientation shown from top to bottom, and the vertical acceleration duration record. The red arrows indicate the time warnings were issued and seismic intensities were estimated. The green arrows indicate the time of maximum vibration and the measured seismic intensities; the estimated seismic intensities were consistent with the measured intensities. Yilan Elementary School is located only $10 \mathrm{~km}$ from the epicenter, but it still had $9 \mathrm{~s}$ of warning time. Chung Cheng University, which is far from the epicenter, had 28 s of warning time.

\section{Conclusion}

Because of its unique geographical environment, earthquake disasters occur frequently in Taiwan. The Central Weather Bureau collated earthquake data from between 1901 and 2006 (Central Weather Bureau, 2007) and found that 97 earthquakes had occurred, of which, 52 resulted in casualties. The 921 Chichi Earthquake had the most profound impact. Because earthquakes have instant destructive power and current scientific technologies cannot provide precise early warnings in advance, earthquake prevention is crucial. The earthquake early warning system can provide seconds to tens of seconds of warning time before an earthquake strikes. Although the warning time is short, it is sufficient for implementing earthquake prevention measures and finding shelter. The National Center for Research on Earthquake Engineering has studied the core technologies for over 10 years; the prototype systems have all passed the triaxial vibration table test of the National Center for Research on Earthquake Engineering and on-site verification tests. The National Center for Research on Earthquake Engineering is progressively promoting and applying the actual machine using a series of customized developments and tests to provide the Taiwanese people with more advanced earthquake prevention devices and to limit the damage caused by earthquakes.
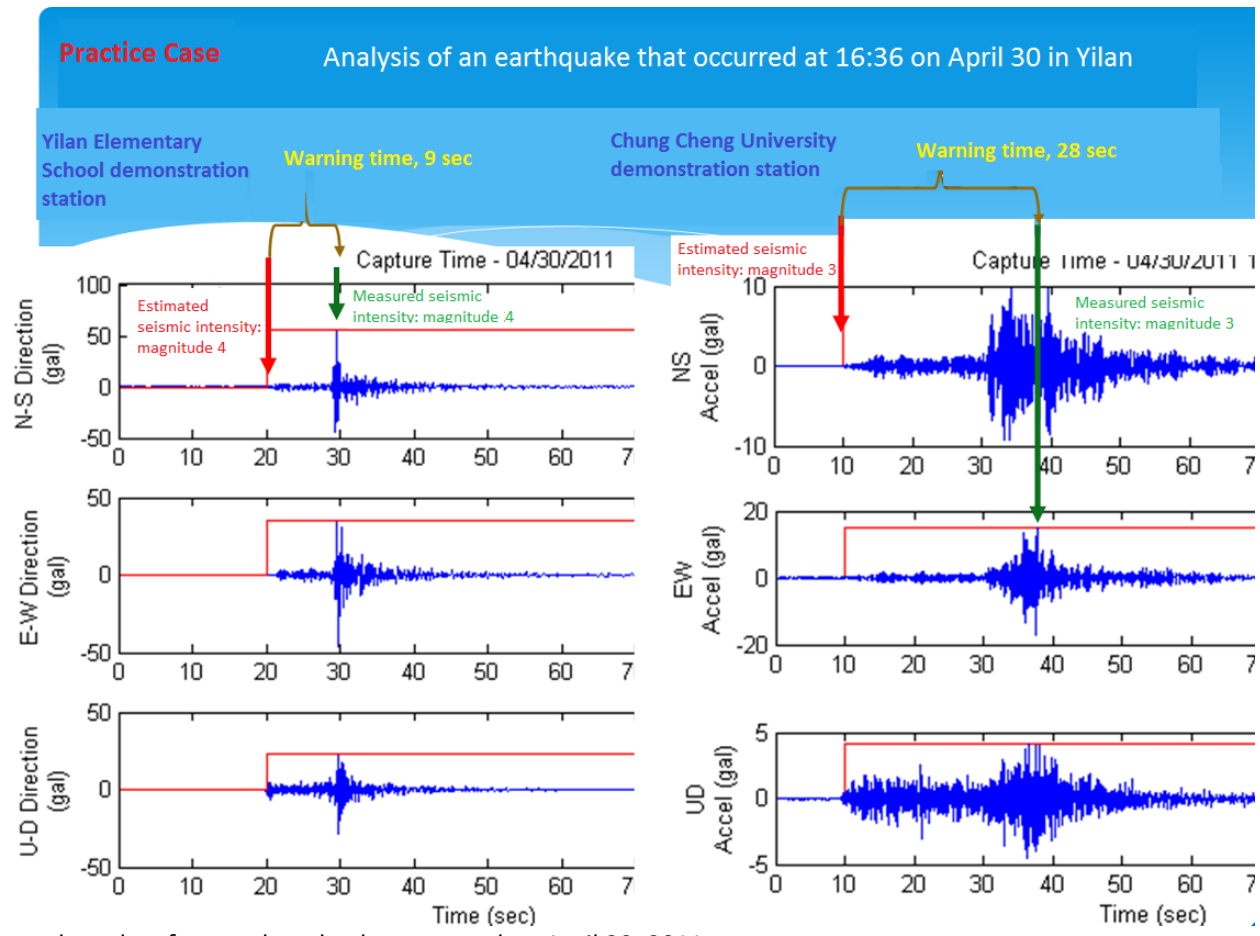

Figure 8. The measured results of an earthquake that occurred on April 30, 2011.

www.ausmt.org 


\section{References}

[1] R. M. Allen, "The Elarms earthquake early warning methodology and its application across California," in Earthquake early warning systems, P. Gasparini, G. Manfredi, and J. Zschau, Eds., 2007, pp. 21-44.

[2] K. Bani-Hani, J. Ghaboussi, and S. P. Schneider, "Experimental study of identification and control of structures using neural network. Part 1 : Identification," Earthquake Engineering \& Structural Dynamics, vol. 28, no. 9, pp. 995-1018, 1999.

doi:

10.1002/(SICI)1096-9845(199909)28:9<995::AID-E QE851>3.0.CO;2-8

[3] J. A. Blume, "Dynamic characteristics of multistory buildings," Journal of the Structural Division, vol. 94, no. 2, pp. 377-402, 1968.

[4] a. G. Chassiakos and S. F. Masri, "Modelling unknown structural systems through the use of neural networks," Earthquake Engineering \& Structural Dynamics, vol. 25, no. 2, pp. 117-128, 1996.

doi:

10.1002/(SICI)1096-9845(199602)25:2<117::AID-E QE541>3.0.CO;2-A
[5] C. S. Huang, S. L. Hung, C. M. Wen, and T. T. Tu, "A neural network approach for structural identification and diagnosis of a building from seismic response data," Earthquake Engineering \& Structural Dynamics, vol. 32, no. 2, pp. 187-206, 2003.

doi: $10.1002 /$ eqe. 219

[6] A. Joghataie, J. Ghaboussi, and X. Wu, "Learning and architecture determination through automatic node generation," in International Conference on Artificial Neural Networks in Engineering, New York, 1995.

[7] R. R. Leach and F. U. Dowla, "Earthquake early warning system using real-time signal processing," in Neural Networks for Signal Processing, Kyoto, Japan, 1996, pp. 463-472.

doi: $10.1109 /$ NNSP.1996.548376

[8] C. C. J. Lin, "A neural network-based methodology for generating spectrum-compatible earthquake accelerograms," Ph.D. dissertation, University of Illinois at Urbana-Champaign, Champaign, IL, USA, 2000.

[9] G. Wurman, R. M. Allen, and P. Lombard, "Toward earthquake early warning in northern California," Journal of Geophysical Research, vol. 112, no. 2007. doi: $\underline{10.1029 / 2006 J B 004830}$ 